RU Ценностная репрезентация гендерных стереотипов посредством паремий, содержащих номинацию пола (на материале английских и русских пословиц)

\author{
Шаймарданова М. Р., Ахметова Л. А.
}

Аннотация. Цель исследования - выявить способы репрезентации ценностных этнокультурных концептов, стереотипных оценок по отношению к представителям того или иного пола посредством проведения сравнительного анализа гендерно-маркированных английских и русских пословиц. Научная новизна исследования заключается в комплексном сравнительном анализе оценочной семантики английских и русских пословиц, репрезентирующих гендерные стереотипы. В результате выделены и охарактеризованы: семантические группы пословиц, содержащих номинацию пола, которые наиболее ярко представляют оценочные гендерные стереотипы исследуемых социумов; общие и специфичные характеристики оценочной семантики паремий; оценочные представления этносов о представителях полов, транслируемые посредством пословиц с гендерным компонентом.

\title{
Value Representation of Gender Stereotypes through Paroemias Containing Gender Nomination (Based on English and Russian Proverbs)
}

\author{
Shaimardanova M. R., Akhmetova L. A.
}

\begin{abstract}
The aim of the study is to identify the ways of representing ethno-cultural value concepts, stereotypical evaluations in relation to representatives of one gender or another through a comparative analysis of gender-marked English and Russian proverbs. The scientific originality of the research lies in a comprehensive comparative analysis of the evaluative semantics of English and Russian proverbs that represent gender stereotypes. As a result, the following were identified and characterized: the semantic groups of proverbs containing gender nomination, which most clearly represent the evaluative gender stereotypes of the studied societies; the general and specific characteristics of the evaluative semantics of paroemias; the evaluative ideas of ethnic groups about the representatives of the genders, transmitted through proverbs with a gender component.
\end{abstract}

\section{Введение}

Ценностная репрезентация национальной картины мира ярко представлена паремиологическим фондом языка, в котором пословицы занимают доминантное место среди разнообразия жанров. В связи с тем, что паремиологический фонд языка обладает функцией культурно-рефлексивной стереотипизации (Семененко, 2011, с. 29), являющейся важнейшей когнитивно-прагматической функцией и делающей паремии универсальными прецедентными единицами, мы можем заявить о значимости пословиц в аспекте ценностно-смыслового пространства. Данный факт обуславливает актуальность темы настоящего исследования.

Для достижения цели исследования необходимо решить следующие задачи:

- выявить и классифицировать в паремиологических фондах английского и русского языков пословицы, содержащие номинацию обоих полов;

- провести системный анализ семантики паремий с точки зрения их отражения ценностной репрезентации гендерных стереотипов в обоих рассматриваемых языках;

- выделить общие и уникальные ценностные представления о полах в рассматриваемых социумах посредством гендерно-маркированных паремий.

В статье применяются следующие методы исследования: метод научного наблюдения, сравнительносопоставительный метод, описательный метод, метод количественного подсчета. 
Материал исследования составили английские и русские пословицы, поговорки, полученные методом специальной выборки из следующих паремиологических сборников: G. B. Bryan \& W. Mieder “A Dictionary of AngloAmerican Proverbs and Proverbial Phrases”, A. Bertram “NTC's Dictionary of Proverbs and Cliches”, W. Mieder “English Proverbs”, В. Stevenson “The Home Book of Proverbs, Maxims and Familiar Phrases”, Аникин В. П. «Русские пословицы и поговорки», Ю. В. Мюррей «Русские пословицы, поговорки и фразеологизмы и их английские аналоги», И. М. Снегирев «Русские народные пословицы и притчи», М. В. Буковская и др. «Словарь употребительных английских пословиц», В. И. Даль «Пословицы русского народа» и др.

Теоретической базой исследования послужили работы ученых-паремиологов: Н. Н. Семененко, О. Б. Абакумовой, Н. Ф. Алиференко, Г. Ш. Хакимовой; а также исследователей лингвистической гендерологии: А. В. Кирилиной, Е. В. Грищенко, Л. С. Поляковой и др.

Практическая значимость исследования заключается в том, что полученные результаты могут быть использованы при разработке спецкурсов по сопоставительной паремиологии, лингвофольклористике, лингвокультурологии, а также гендерной лингвистике.

\section{Основная часть}

Рассматриваемые паремиологические единицы представляют в языке и культуре некоторый свод прагматических установок, нацеленных на сохранение и трансляцию идейных основ национальной культуры. Используя когнитивно-прагматический подход, Н. Н. Семененко (2017, с. 3) рассматривает пословицы как особую группу прецедентных единиц языка, так как паремии представляют собой средство выражения мировоззрения этноса, существующего и формирующегося в культуре, подверженного влиянию множества факторов и внутренних противоречий. Ученый понимает ценностную репрезентацию как вербализацию когнитивных единиц: концептов, категорий, понятий, фреймов и т.д., содержательно соотносимых с ценностями культуры, бытия социума и человека (с. 26).

Ввиду антропоцентрической направленности современной лингвистики исследование семантики паремиологических единиц соответствует тенденции лингвистической науки исследовать корреляцию языка и культуры при проведении анализа вторичных номинативных единиц языка, репрезентирующих те или иные культурные смыслы.

Семантика пословиц обладает неким набором специфических характеристик, важнейшей из которых является оценка, представляющая собой главный критерий формирования прагматической установки культуры.

Согласно О. Б. Абакумовой (2013), существуют следующие типы оценки: «..первый тип отражает ценности данной культуры, представленный в семантике пословицы имплицитно, и кодируется разными лингвистическими средствами, другой связан с коммуникативной стратегией говорящего» (с. 118).

При социализации языковой личности наблюдается одновременный взаимосвязанный с ней процесс формирования иерархии ценностей. Становление же национальной языковой личности тесно коррелирует с осознанием когнитивной базы определенного лингвокультурного социума, содержащей прецедентные феномены и стереотипы (Гудков, 1999; Красных, 2003), ярко представленные в паремическом фонде того или иного этноса.

Стереотипизация суждений и оценок находит свое яркое выражение в паремиологических текстах, являясь их доминирующей функцией, т.к. с помощью данной функции репрезентирован дидактический потенциал народных изречений.

Н. Ф. Алефиренко (2009) определяет языковые стереотипы этнокультурного характера как «объективированные в языке профилированные концепты, понятия, признаки окружающей человека действительности, которые составляют лингвокогнитивную конфигурацию языковой картины мира. Поскольку языковые стереотипы порождаются этнически обусловленными представлениям, сформированными фольклорно-мифологическим сознанием и бытующими в системе традиционной лингвокультуры, в основе их содержания лежат не просто оценочные образы, зафиксированные в языке (номинативных моделях, фраземах и паремиях). Когнитивным субстратом каждого языкового стереотипа является один из этнокультурных концептов, фундаментирующих базовые топики языковой картины мира» (с. 67).

Согласно А. А. Константиновой (2007), «стереотипы - прочно сложившиеся представления, определенные штампы сознания, специфичные для того или иного народа, носителя языка - являются элементами его когнитивной базы. Любой стереотип есть прецедентный феномен. На этом основании паремии могут изучаться как их разновидность - прецедентные высказывания» (с. 8).

Н. Н. Семененко (2017) определяет пословицу как «паремический жанр, являющийся средством формирования стереотипных оценок и рекомендаций по отношению к типичным жизненным ситуациям. Основными семантическими характеристиками пословиц выступают: (а) обобщенная природа значения; (б) “прозрачная” метафорически организованная внутренняя форма; (в) поликонцептуальность смысловой структуры» (с. 3).

Г. Ш. Хакимова (2003) подчеркивает, что паремика, являясь чрезвычайно информативным материалом для анализа того или иного концепта, выражает застывшее осознание, образовавшееся в течение длительного периода, «она дает “усредненную”, стереотипную картину мира и выражает оценку в эксплицитной форме» (с. 88).

А. В. Кирилина видит паремику в качестве маркера культурных стереотипов, сформированных в языке (Кирилина, 1999, с. 85).

Важность исследования основных стереотипов этноязыкового сознания при формировании семантического и прагматического содержания пословиц объясняется способностью данных паремиологических 
единиц репрезентировать основные мыслительные характеристики этноязыкового сознания, реализовывать инкультурацию индивида в ходе овладения компромиссной моралью, включающей всестороннюю оценку ситуации. Пословичные изречения, известные своей догматичностью, все же проявляют неоднозначность в оценке, а также являются полифоничными по отношению к ценностям культуры.

Н. Н. Семененко (2017) представляет речевую формулу паремии как «народную мораль на “фоне” стереотипного осмысления множества типических ситуаций под “прицелом” определенных ценностных доминант народного сознания» (с. 4).

В ходе настоящего сопоставительного исследования предполагается выявить общие и специфичные характеристики оценочной семантики паремий; как следствие обнаружить и сравнить гендерные оценочные стереотипы исследуемых этносов.

Отличительные характеристики семантической структуры паремий с гендерным компонентом представляют собой некий обобщенный свод знаний, касающихся взаимоотношений между представителями разных полов, взаимоотношений между родственниками, а также стереотипного гендерного поведения в ходе повторяющихся ситуаций общения. Идейное содержание пословиц с гендерным компонентом осмысляется нашим разумом безраздельно и собирательно излагает принятые стандарты форм поведения репрезентантов разных полов в тех или иных жизненных обстоятельствах в семье, в обществе.

Гендерно-маркированные паремии являются одним из объектов исследования гендерной лингвистики. А. В. Кирилина (1999) заявляет о том, что «целью гендерных исследований в языке может быть изучение речевого поведения полов, выделение и описание мужского и женского речевых рисунков» (с. 36).

Е. В. Грищенко (2010) рассматривает цель лингвистической гендерологии как «изучение гендерных признаков языковой картины мира, речевого поведения мужчин и женщин с учетом культурной традиции данного общества, гендерных стереотипов и исторически изменчивых концептов мужественности и женственности, женского и мужского видения мира, проявления женских и мужских способов речевой самореализации» (с. 10).

Говоря об объекте исследования лингвистической гендерологии, Л. С. Полякова (2007) заявляет, что им «становятся взаимоотношения языка и пола, то есть вопрос о том, каким именно образом пол манифестируется в языке - в номинативной системе, лексике, синтаксисе, категории рода и т.д.» (с. 49). Основной целью, по мнению ученого, становится описание и объяснение того, «как пол проявляется в языке, какие оценки приписываются в языке мужчинам и женщинам и в каких семантических областях они наиболее распространены» (с. 49).

Паремии играют значимую роль при исследовании гендерной проблематики. Являясь важным пластом языка, паремиологический фонд позволяет выявить гендерные стереотипы того или иного народа, что способствует формированию оценочного суждения по отношению к полам.

Данная работа посвящена анализу английских и русских гендерно-маркированных пословиц, выражающих оценочные стереотипы по отношению к поведению и внутреннему миру представителей полов исследуемых этносов. Для проведения исследования нами были отобраны английские и русские пословицы с гендерным компонентом, содержащие следующие ключевые слова, являющиеся номинацией пола: женщина, баба, жена, woman, wife; мужчина, муж, мужик, man, gentleman, husband, he.

Анализ фактологического материала предоставил возможность классифицировать исследуемые паремии по двум семантическим группам, которые, на наш взгляд, наиболее ярко отражают стереотипные оценки по отношению к представителям полов:

1. поведение;

2. внутренний мир.

Приведенные Таблицы 1-2 наглядно представляют результаты проведенного анализа. Данные таблицы демонстрируют процентное соотношение пословиц с позитивной и негативной оценочной семантикой от общего количества рассматриваемых паремий, входящих в ту или иную семантическую группу.

Таблица 1. Частотность английских паремий с позитивной и негативной оценочной семантикой

\begin{tabular}{|l|c|c|c|c|c|c|}
\hline \multirow{2}{*}{$\begin{array}{c}\text { Семантическая } \\
\text { группа }\end{array}$} & \multicolumn{3}{|c|}{ Мужчина } & \multicolumn{2}{c|}{ Женщина } \\
\cline { 2 - 7 } & Всего & Позитив & Негатив & Всего & Позитив & Негатив \\
\hline Поведение & $12 / 8,5 \%$ & $9 / 6,4 \%$ & $3 / 2,1 \%$ & $34 / 23 \%$ & $8 / 5,5 \%$ & $26 / 17,5 \%$ \\
\hline Внутренний мир & $19 / 14 \%$ & $3 / 2,5$ & $16 / 11,5 \%$ & $47 / 32 \%$ & $8 / 5,5 \%$ & $39 / 26,5$ \\
\hline
\end{tabular}

Таблица 2. Частотность русских паремий с позитивной и негативной оценочной семантикой

\begin{tabular}{|l|c|c|c|c|c|c|}
\hline \multirow{2}{*}{$\begin{array}{c}\text { Семантическая } \\
\text { группа }\end{array}$} & \multicolumn{3}{|c|}{ Мужчина } & \multicolumn{2}{c|}{ Женщина } \\
\cline { 2 - 7 } & Всего & Позитив & Негатив & Всего & Позитив & Негатив \\
\hline Поведение & $22 / 22,5 \%$ & $3 / 3 \%$ & $19 / 19,5 \%$ & $63 / 21 \%$ & $50 / 17 \%$ \\
\hline Внутренний мир & $17 / 17,5 \%$ & $10 / 10,2 \%$ & $7 / 7,3 \%$ & $106 / 35 \%$ & $13 / 4 \%$ & $93 / 31 \%$ \\
\hline
\end{tabular}

Как видно из таблиц, представительницы женского пола наиболее подвержены оценке со стороны социума посредством паремиологических единиц, т.к. и английская, и русская паремиологические картины миpa (ПКМ) содержат большее число паремий, репрезентирующих оценочную семантику по отношению к женщинам. Более того, данные, представленные в таблицах, демонстрируют преобладание негативного отношения к женщинам в обоих рассматриваемых этносах. 
При рассмотрении гендерно-маркированных пословиц, содержащих номинацию мужского пола, обнаруживается более лояльная оценка мужчин исследуемыми социумами. Например, в английской ПКМ поведение мужчин оценивается скорее позитивно (6,4\%), чем негативно $(2,1 \%)$. Аналогичная картина наблюдается и в русской паремике: пословицы, описывающие внутренний мир русского мужчины, насчитывают большее количество паремий с положительной оценочной семантикой (позитивная оценка - 10, негативная оценка - 7).

Семантическая группа «внутренний мир» как в английской, так и в русской ПКМ является наиболее частотной и, на наш взгляд, представляет собой ярчайший маркер ценностной репрезентации национальной картины мира по отношению к полам.

Внутренний мир английской и русской женщин в паремиологии в целом схож. Как было отмечено ранее, образ женщин обоих рассматриваемых этносов носит отрицательно-коннотированный характер. Следующие качества выражают негативную оценку внутреннего мира женщины в обоих рассматриваемых паремиологических картинах мира: глупость, хитрость, злость, своенравность, непостоянство, двуличие, лень.

Women have long hair and short brains (Fergusson, 1995, с. 89). / Женский волос долог, а ум короток (здесь и далее перевод автора статьи. - М. Ш.); Баба дура (Снегирев, 2010, с. 46); У бабы волос долог, да ум короток (Жуков, 1991, с. 328);

The greatest water power known to man is a woman's tears (Котий, Тюленев, 2012, с. 21). / Мощнейшая сила воды, известная человеку, - это женские слезы; Баба и черта перехитрит (Аникин, 1988, с. 15);

Women are like wasps in their anger (Stevenson, 1956, с. 2104). / Женщины в гневе похожи на ос; Всех злее злых злая жена (Даль, 1993, с. 121);

Woman will have both her word and her way (Stevenson, 1956, с. 2100). / У женщин на все есть свое мнение и свое решение; Бабе хоть кол на голове теши (Даль, 1993 с. 64);

A woman's mind and winter wind change oft (Мюррей, 2008, с. 7). / Женский разум также переменчив, как зимний ветер; У бабы семь пятниц на неделе (Даль, 1993, с. 64);

God save us from all wives who are angels in the street, saints in the church and devils at home (Stevenson, 1956, с. 1900). / Господи, убереги нас от жен, которые ведут себя как ангелы на людях, как святые в церкви и как ведьмы дома; В людях - ангел, не жена: дома с мужем - сатана (Мюррей, 2008, с. 27);

The more women look in their glass, the less they look at their house (Мюррей, 2008, с. 46). / Чем больше женщины смотрятся в зеркало, тем меньше они уделяют внимания хозяйству; Где бабы гладки, там нет воды в кадке (Мюррей, 2008, с. 46).

Кроме того, женщина в английской паремике характеризуется бездушностью: Women have no souls (Mюpрей, 2008, с. 107). / У женщин отсутствует душа; жадностью: Women, priests and poultry, have never enough (Мюррей, 2008, с. 127). / Женщины, священники и домашние птицы всегда ненасытны; самовлюбленностью: A vain woman is like an empty egg-shell (Bryan, Mieder, 2005, с. 855). / Самовлюбленная женщина подобна пустой яичной скорлупе.

Русская ПКМ наделяет женщину лживостью в дополнение к вышеперечисленным отрицательным характеристикам: Баба бредит, кто ей верит (Снегирев, 2010, с. 46); Бабьи враки - девичьи присухи; Бабы врут, девкам присуху дают (Даль, 1993, с. 195).

В противоположность ярко репрезентированному в паремике обоих исследуемых языков негативно окрашенному образу женщины, положительный образ демонстрируется в ПКМ очень скудно и состоит из следующих немногочисленных характеристик:

трудолюбие, доброта, ум:

One hair of a woman draws more than a team of horses (Bryan, Mieder, 2005, с. 345). / Один женский волос вытянет больше, чем несколько лошадей; Жена хороша не телом, а делом (Снегирев, 2010, с. 165);

In the husband wisdom, in the wife gentleness (Мюррей, 2008, с. 128). / Мужу мудрость, жене доброта; С доброй женой горе - полгоря, а радость вдвойне (Даль, 1993, с. 109);

A wise woman is one who has a great deal to say, and remains silent (Котий, Тюленев, 2012, с. 20). / Мудрая женщина - это та, что, желая высказаться, остается молчаливой; A woman's counsel is sometimes good (Stevenson, 1956, с. 2100). / Женский совет иногда бывает полезен; Умная жена, как нищему сума (Даль, 1993, с. 109).

Отрицательно-коннотированный образ женщины в обоих ПКМ дополняется паремиями, входящими в семантическую группу поведение. Данные приведенных таблиц отражают гендерный стереотип негативной оценки женского поведения в исследуемых языках.

Негативная оценка женского поведения, репрезентированная в паремиях рассматриваемых этносов, выражена следующими характеристиками: болтливость, слезливость, суетливость (неуемность), блудливость, бранчливость, кокетство (щегольство):

A woman's tongue wags like a lamb's tail (Stevenson, 1956, с. 2100). / Женщина вертит языком, как ягненок хвостом; Бабий кадык не заткнешь ни пирогом, ни рукавицей (Даль, 1993, с. 65);

There is nothing sooner dry than a woman's tears (Котий, Тюленев, 2012, с. 22). / Женские слезы дешевы; Без плачу у бабы дело не спорится (Даль, 1993, с. 66);

Three women make a market (Мюррей, 2008, с. 223). / Где три женщины, там - базар; Где две бабы, там суем, а где три, там содом (Даль, 1993, с. 64);

Three things to stay away from: a snake, a man with an oily tongue, and a loose woman (Bryan, Mieder, 2005, c. 769). / Змея, льстивый мужчина и распутная женщина - это то, от чего следует держаться подальше; Баба блудит, а деду грех (Даль, 1993, с. 548); 
Happy is the deaf man that has a scolding wife (Stevenson, 1956, с. 1915). / Только глухой мужчина будет счастлив с бранчливой женой; Жена бранчлива - мужу позор (Аникин, 1988, с. 96);

Баба вертится задом, передом, а дело идет чередом (Снегирев, 2010, с. 46).

В дополнение к этому в английском языке присутствуют пословицы, характеризующие женщину как хрупкое, морально слабое существо: A woman and a ship ever want mending (Bertram, 1993, с. 137). / Женщина и корабль всегда нуждаются в заботе; A woman and a glass are over in danger (Mieder, 2008, с. 128). / Женщины такие же хрупкие, как стекло; Frailty, thy name is woman (Stevenson, 1956, с. 537). / Имя женщины - хрупкость, что, по нашему мнению, также имеет тенденцию к негативному оцениванию со стороны социума. Однако русский паремиологический фонд, напротив, демонстрирует силу духа женщины (что относится к положительной оценке): Баба не квашня: встала, да и пошла (Даль, 1993, с. 64).

Отбор гендерно-маркированных пословиц обоих исследуемых этносов, выражающих положительную оценку женского поведения, выявил единственную положительную характеристику семантической группы «поведение» - хозяйственность: Men get wealth, and women kept it (Stevenson, 1956, с. 843). / Мужчина обеспечивает достаток, а женщина хранит его; Men make houses, women make homes (Bertram, 1993, c. 148). / Мужчины строят дома, а женщины организуют уют; Баба с кашкой, а дед с ложкой (Аникин, 1988, с. 15); Баба с кромою, а дед с сумою (Даль, 1993, с. 65), Баба, что мешок: что положишь, то и несет (Даль, 1993, с. 67); Пусти бабу в рай: она и корову за собой приведет (Даль, 1993, с. 66).

При исследовании стереотипных гендерных оценок по отношению к мужчинам в паремиологических картинах мира рассматриваемых языков было обнаружено гораздо меньшее число пословиц (по сравнению с гендерными оценками женщин), дающих оценочные представления этих этносов. В обоих исследуемых социумах наиболее ярко выраженной отрицательной характеристикой внутреннего мира мужчины является трусость:

He that feareth every bush must never go a-birding (Буковская, 1988, с. 304). / Тот, кто ждет опасности за каждым кустом, не должен ходить в лес; He that fears death lives not (Буковская, 1988, с. 202). / Тот, кто боится смерти, не живет.

Исследование положительной оценки внутреннего мира мужчин обоих рассматриваемых социумов позволило выявить такую положительную характеристику, как мудрость:

In the husband wisdom, in the wife gentleness (Мюррей, 2008, с. 128). / Мужу - мудрость, жене - доброта; У умного мужа и глупая жена досужа (Даль, 1993, с. 104); Мужик-то сер, а ум-то у него не волк (не черт) съел (Аникин, 1988, с. 188).

Семантическая группа поведение более ярко представлена в паремике исследуемых этносов. Паремии с положительной семантикой демонстрируют следующие качества, общие для рассматриваемых языков:

Хозяйственность, честность:

Men make houses, women make homes (Bertram, 1993, с. 148). / Мужчины строят дома, а женщины организуют уют в домах; Мужик добрый не проказник, работает и в праздник (Жуков, 1991, с. 179);

An honest man's word is as good as his bond (Мюррей, 2008, с. 226). / Слова честного мужчины так же верны, как его обещания; Правдивому мужу лукавство не под нужду (Даль, 1993, с. 17).

Исследуя паремии с негативной оценочной семантикой, мы столкнулись с явлением непохожести гендерных оценочных стереотипов исследуемых паремиологических фондов. Паремика английского языка характеризует поведение мужчины как глупое (подобное обезьяне): A man is an ape in velvet (Bryan, Mieder, 2005, с. 493). / Мужчина - это обезьяна, одетая в бархат; скандальное: A quarrelsome man has no good neighbours (Mieder, 2008, с. 79). / У скандального мужчины все соседи плохие.

Поведению мужчины в русской паремике приписывается множество негативных характеристик: разгильдяйство, ревность, лживость (скрытность), пьянство, блудливость: Жена прядет, а муж пляшет (Даль, 1993, с. 104); За ревнивым мужем быть - не в корысти свою молодость износить (Снегирев, 2010, с. 544); Не всякую правду муж жене сказывает, а и сказывает, так обманывает (Даль, 1993, с. 108); Мужик год не пьет, и два не пьет, а как черт прорвет, так и все пропьет (Жуков, 1991, с. 177); У кого на уме молитва да пост, а у него бабий хвост (Даль, 1993, с. 208).

Данное исследование продемонстрировало уникальность пословицы, которая заключается в способности паремии не только отражать сформированные социумом концепты и общепринятые стереотипы, но также транслировать отношение народа к данным аспектам картины мира, их ценностные смыслы.

\section{Заключение}

Проведенный анализ позволяет сформулировать следующие выводы:

- гендерно-маркированные пословицы, являясь показателем оценочных гендерных стереотипов, представляют сложившиеся десятилетиями суждения и оценки социума по отношению к представителям полов;

- в обоих рассматриваемых паремиологических фондах большее внимание уделяется оцениванию представительниц женского пола;

- портрет женщины как в английской, так и в русской ПКМ оценивается исследуемыми этносами скорее отрицательно;

- в обоих исследуемых ПКМ наблюдается преобладание положительного оценивания к представителям мужского пола, несмотря на то, что паремики английского и русского языков репрезентируют портрет мужчины по-разному. 
Перспективы дальнейшего исследования авторам видятся в последующем исследовании репрезентации гендерных оценочных стереотипов посредством паремий в художественном, политическом и других видах дискурсов, что расширит спектр имеющихся знаний о паремиологических картинах мира исследуемых языков.

\section{Источники | References}

1. Абакумова О. Б. Пословичные концепты в паремическом дискурсе: дисс. ... д. филол. н. Орел, 2013.

2. Алефиренко Н. Ф., Семененко Н. Н. Фразеология и паремиология: учебное пособие для бакалаврского уровня филологического образования. М.: Флинта; Наука, 2009.

3. Аникин В. П. Русские пословицы и поговорки. М.: Художественная литература, 1988.

4. Буковская М. В., Вяльцева С. И., Дубянская З. И. и др. Словарь употребительных английских пословиц. Изд-е 2-е, стер. М.: Рус. яз., 1988.

5. Грищенко Е. В. Гендерный аспект современного политического мы-дискурса // Вісник ЛнУ імені Тараса Шевченка. 2010. № 20 (207). Ч. І.

6. Гудков Д. Б. Прецедентное имя и проблемы прецедентности. М.: Изд-во МГУ, 1999.

7. Даль В. И. Пословицы русского народа: в 3-х т. М.: Русская книга, 1993. Т. 2.

8. Жуков В. П. Словарь русских пословиц и поговорок. Изд-е 4-е, испр. и доп. М.: Русс. яз., 1991.

9. Кирилина А. В. Гендер: лингвистические аспекты. М.: Институт социологии РАН, 1999.

10. Красных В. В. «Свой» среди «чужих»: миф или реальность? М.: Гнозис, 2003.

11. Константинова А. А. Коммуникативно-прагматический потенциал пословиц и поговорок в современной англо-американской прессе: автореф. дисс. ... к. филол. н. Тула, 2007.

12. Котий Г. А., Тюленев С. В. Английские афоризмы и пословицы / под ред. А. С. Дробашенко. М.: Астрелб, 2012.

13. Мюррей Ю. В. Русские пословицы, поговорки и фразеологизмы и их английские аналоги. М. - СПб.: АСТ; Сова, 2008.

14. Полякова Л. С. Проявление гендерных стратегий в языке политика: на материале английского и русского языков: автореф. дисс. ... к. филол. н. Челябинск, 2007.

15. Семененко Н. Н. Когнитивно-прагматическая парадигма паремической семантики (на материале русского языка): автореф. дисс. ... д. филол. н. Белгород, 2012.

16. Семененко Н. Н. Русские паремии: функции, семантика, прагматика. Старый Оскол: Изд-во РОСА, 2011.

17. Семененко Н. Н. Стереотипизированная мораль как ценностный субстрат семантики пословицы // Концепт: научно-методический электронный журнал. 2017. № 12. URL: http://e-koncept.ru/2017/175015.htm

18. Снегирев И. М. Русские народные пословицы и притчи. М.: Эксмо, 2010.

19. Хакимова Г. Ш. Гендерный фактор в английских паремиях в сопоставлении с русскими: дисс. ... к. филол. н. Уфа, 2003.

20. Bertram A. NTC's Dictionary of Proverbs and Cliches. Lincolnwood - Illinois: NTC Publishing Group, 1993.

21. Bryan G. B., Mieder W. Anglo-American Proverbs and Proverbial Phrases Found in Literary Sources of the Nineteenth and Twentieth Centuries. N. Y.: Peter Lang Publishing, 2005.

22. Fergusson R. The Penguin Dictionary of Proverbs. Second edition. Middlesex: Penguin B.S., 1995.

23. Mieder W. English Proverbs. Stuttgart: Philipp Reclam, 2008.

24. Stevenson B. The Home Book of Proverbs, Maxims and Familiar Phrases. N. Y.: The MacMillan Company, 1956.

\section{Информация об авторах | Author information}

RU Шаймарданова Миляуша Равилевна ${ }^{1}$, к. филол. н.

Ахметова Лейсан Атласовна ${ }^{2}$, к. филол. н.

1,2 Елабужский институт Казанского федерального университета

EN Shaimardanova Milyausha Ravilevna ${ }^{1}, \mathrm{PhD}$

Akhmetova Leysan Atlasovna ${ }^{2}$, PhD

${ }^{1,2}$ Elabuga Institute of Kazan Federal University

${ }^{1}$ milyausha33@mail.ru,2leisan81@mail.ru

\section{Информация о статье | About this article}

Дата поступления рукописи (received): 18.09.2021; опубликовано (published): 29.10.2021.

Ключевые слова (keywords): пословицы с гендерным компонентом; паремии; гендерные стереотипы; ценностная репрезентация; прецедентные единицы; proverbs with a gender component; paroemias; gender stereotypes; value representation; precedent units. 